2020

Revista Vol. 23(46)

Prolegómenos julio-diciembre 2020

\title{
La importancia simbólica del Derecho y los fundamentos del Ius Utrumque*
}

\author{
José Guillermo Castro Ayala
}

\begin{abstract}
Resumo: El presente artículo ofrece una lectura al proceso de recepción del derecho romano en los sistemas jurídicos europeos desde la Alta Edad Media. Las reformas de Gregorio viI, el papel de la escuela de Boloña, la búsqueda de sistematización del derecho canónico y el redescubrimiento de las enormes fuentes del derecho romano fueron el punto de partida para un proceso de racionalización del derecho que conserva el carácter simbólico que poseía el derecho canónico. Esto permitió la expansión de elementos jurídicos en toda Europa que conformaron un denominador común para la época: el Ius Utrumque.
\end{abstract}

Palabra clave: exploração sexual comercial; Peru; trabalho infantil

Recibido: 05 de junio de 2018 Aceptado: 22 de abril de 2020

Disponible en línea: día, mes y año.

Cómo citar: Castro Ayala, J. G. (2020). La importancia simbólica del Derecho y los fundamentos del Ius Utrumque. Prolegómenos, 23(46). 121-132. DOI: https://doi.org/10.18359/prole.4308

* Artículo de reflexión resultado del proyecto de investigación titulado "La semiología del Derecho y los fundamentos del Ius Utrumque", adscrito al grupo de investigación Grupo de investigación en propiedad intelectual y derecho privado de la Universidad Católica de Colombia.

a Doktor Juris, Magna cum Laude (Universität Konstanz, Alemania); Magister Llegum, Cum Laude (Universität Konstanz, Alemania); Magíster (Universidad Nacional de Colombia); Abogado (Universidad Nacional de Colombia). Es profesor por concurso de Derecho Civil de la Facultad de Derecho de la Universidad Nacional de Colombia, Bogotá, Colombia. Correo electrónico: castroayal@googlemail.com. ORCID: 


\section{The symbolic importance of Law and the foundations of the Utrumque Ius}

Abstract: This article offers a reading of the acceptance of Roman law in the European legal systems since the High Middle Ages. Gregory VII's reforms, the role of the Bologna school, the search for systematization of canon law and the rediscovery of the enormous sources of Roman law were the starting point for a process of rationalization of law that retains the symbolic character that canon law possessed. This allowed the expansion of legal elements throughout Europe that formed a common denominator for the time: the Ius Utrumque.

Keywords: commercial sexual exploitation; Peru; child labor

\section{A importância simbólica do Direito e os fundamentos do jus utrumque}

Resume :Este artigo oferece uma leitura do processo de recepção do direito romano nos sistemas jurídicos europeus desde a Alta Idade Média. As reformas de Gregório VII, o papel da escola de Bolonha, a busca da sistematização do direito canônico e o redescobrimento das enormes fontes do direito romano foram o ponto de partida para um processo de racionalização do direito que conserva o caráter simbólico que o direito canônico apresentava. Isso permitiu a expansão de elementos jurídicos em toda a Europa que formaram um denominador comum para a época: o jus utrumque.

Palavras-chave: Ius Utrumque; acculturation; Roman law; Canon law; Corpus Iuris Civilis 


\section{Introducción}

Una pregunta recurrente para quienes se preocupan por el fenómeno jurídico en América Latina se sintetiza de la siguiente manera: ¿por qué la hiperinflación normativa actual e irrefrenable en todos los países y latitudes no contribuye -por lo menos significativamente- a una mejor organización de las sociedades? Desde la sociología y la antropología social, uno de los primeros diagnósticos sugiere lugares comunes dirigidos a la interiorización de las normas, es decir, a los procesos éticos y morales no necesariamente religiosos que en algunas sociedades fluyeron paralelamente a la invención del derecho y que en otras, estuvieron ausentes.

Así, en la Baja Edad Media europea la interiorización de las normas éticas, morales y religiosas corrió paralela al resurgimiento de la juridicidad en Occidente. Estos procesos históricos, junto a muchos otros ejemplos, no hicieron parte del propio desenvolvimiento del mundo subdesarrollado, entendido como aquellos territorios que no hacen parte de Europa. En efecto, esos procesos que tuvieron lugar de manera tranquila y sosegada en los actuales países desarrollados europeos, jamás se presentaron en los surgientes estados periféricos. Por ejemplo, en América Latina, las campañas libertadoras del siglo XIX, entre otros fenómenos, abocaron intempestivamente a las nacientes repúblicas a la expedición de normas totalmente desconocidas o impertinentes para las incipientes sociedades. Famosa es la carta en la que Jeremy Bentham le propone a Simón Bolívar redactar la normatividad para las nuevas repúblicas; honrosa oferta que al parecer Bolívar alcanzó a tener en consideración (Schwartz y Rodríguez, 1992). De donde se sigue la falta de conexidad que existía entre la realidad y los objetivos legislativos en la época de la emancipación de América Latina.

Así mismo, no se realizaron estudios sobre la organización sociopolítica negra, campesina o indígena en estas latitudes, y ello tiene que ver con los intereses que guardaban solo para sí los criollos. Sobre esto ya ha apuntado Marc Ferro (2000), refiriéndose a la colonización y las consecuencias del eurocentrismo a escala global, al afirmar que para el caso latinoamericano "[los criollos] se apoyaban también en la literatura de la Ilustración -Locke, Rousseau, Adam Smith, etc.- no para defender los derechos de los mestizos o de los indios, sino para combatir el despotismo de los Borbones de España” (p. 279). El resto de población, es decir, todos aquellos que no pertenecían a los criollos, resultaron plenamente excluidos de cualquier clase de discusión sobre su propia autonomía legislativa $y$, por supuesto, negocial en las nacientes repúblicas. Luego de estas mínimas observaciones, la sugerencia que parece consolidarse es que la simple implementación de normas sin procesos sociales, simbólicos, éticos o moralizantes, conduce a una significativa inutilidad de los sistemas jurídicos impuestos.

La coyuntura actual vuelve a llamar la atención al respecto: el sino histórico parece oscilar de cortas épocas libertarias, a complejos y largos periodos de conservadurismo retrógrado, que tienden a desordenar y radicalizar nuevamente a los discursos de vanguardia; lo que a su vez estimula nuevas oleadas normativas represivas o eventualmente conciliadoras, que luego desembocan en nuevos periodos libertarios y emancipatorios; en donde, en general, puede observarse otra clase de producción jurídica que parece encontrar acuerdos y sosiegos válidos. Son diversos los estudios que evidencian, desde el aspecto social, económico y jurídico, un paralelismo entre el libertarismo de los primeros catorce años del siglo xx y la década de los noventa del mismo siglo.

En Colombia, los procesos de vanguardia se acentuaron a partir de la renuncia de Rafael Reyes al poder. La contrarreforma a los actos legislativos promulgados durante el quinquenio, en términos de Valencia (1987), fue "en verdad muy progresista en su concepción y sus efectos. La carta de la Regeneración no fue restaurada sino mejorada y civilizada. Este arreglo duraría algún tiempo, hasta finales del decenio de 1920" (p. 154). A su vez, Posada Carbó (2010) concibe la época del centenario como un momento histórico pacífico, precedido por las sangrientas luchas partidistas que fueron el denominador de los conflictos civiles durante el siglo XIX; esto se atribuye, en parte, a las nuevas reformas políticas y jurídicas que trajeron consigo la modernización del país. Por otro lado, en el 
período anterior a la Asamblea Constituyente de los noventa, el Estado estaba sumergido en la violencia y el crimen organizado: las redes criminales del narcotráfico, el nacimiento de movimientos como Muerte a Secuestradores (MAS), la crisis institucional con los eventos del Palacio de Justicia, el desarme del Movimiento 19 de abril (M-19) y la crisis económica de finales de los ochenta, fueron parte de las problemáticas que buscaron respuesta a través de la promulgación de la Constitución Política de 1991 (Palacios, 2003).

El panorama mundial de inicios del siglo $\mathrm{xx}$ y de los años noventa se aborda desde sus efectos globalizadores y sus cambios políticos e institucionales. Así, la Comisión Económica para América Latina y el Caribe (CEPAL) (2002) concibió un primer momento -primera fase de la globalización- como el escenario que implicó una gran movilización de capitales, junto a un proceso migratorio que llevó al crecimiento demográfico y a la concentración de mano de obra en países como Estados Unidos. Este proceso se interrumpió gracias a las guerras mundiales, que llevaron a su vez a la creación de organismos internacionales y de una agenda global por los derechos de los ciudadanos -segunda fase de la globalización-. En los años noventa -tercera fase de la globalización-, el mundo se vio inmerso en la revolución tecnológica, la hegemonía financiera, el planteamiento de los problemas ambientales y la apertura económica y social en los países desarrollados.

La coincidencia es obvia. En los dos periodos comparados - esto es la segunda década del siglo xx y los años noventa del mismo- pueden encontrarse elementos comunes: el cruce de fronteras europeas sin pasaporte, los movimientos globalizadores, la renovación normativa libertaria reflejada en tímidos cambios constitucionales o en la consolidación de un catálogo de derechos. En el primer periodo, estos últimos se truncaron por la ocurrencia de hechos inimaginables que desembocaron en la Primera Guerra Mundial, junto a sus conocidas consecuencias, que se extendieron hasta 1945; y en el segundo periodo, por el ataque a las Torres Gemelas y otra serie de actos terroristas a lo largo de Europa. Así, estos elementos fueron puntos que señalaron la cúspide de un movimiento emancipatorio y civilizador a lo largo de todo el mundo desarrollado. En efecto, así como nadie oportunamente pudo prever la Primera Guerra Mundial en 1913, tampoco parecía imaginable que el siguiente paso a la declarada e irreversible globalización, fuese una concepción altamente restrictiva del derecho y de reversión del mismo proceso globalizador.

La política y la confrontación mediática mundial ahora se enfrenta a temas como el cierre de fronteras; la auscultación metodológica y académica permanente que trata de demostrar -por lo menos en Estados Unidos- que la yihad o guerra santa permanente es, antes que una excepción, una regla generalizada evidente en los cánones de la religión musulmana o la percepción nugatoria de derechos transnacionales o humanitarios por cuenta no solo de gobiernos, sino de políticas en bloque transnacionales como la europea, norteamericana, china o australiana.

Para sintetizar la reflexión, a finales de los años noventa del siglo xx nadie pensaba que la globalización fuese a sufrir ninguna clase de revés. Hoy en día pocos académicos serios se atreven a hacer proyecciones optimistas sobre el fenómeno. Las causas de esa fenomenología pueden buscarse en no pocos momentos históricos. A continuación, se hace referencia específicamente a uno.

\section{La recepción del derecho romano canónico}

Para los juristas de nuestra época, el derecho se compone de los ordenamientos jurídicos nacionales. En general, el derecho está vinculado a los estados particulares; así mismo, la ciencia jurídica se ha orientado de manera nacional e interpreta el ordenamiento jurídico válido para el Estado que lo ha expedido. Sin embargo, en épocas en las que la globalización se retrotrae de manera significativa, no por su novedad -como sugieren algunos, pues en realidad esa novedad no existe-, sino por fundamentarse en los últimos tiempos en pilares equivocados, vale de nuevo recordar que en Europa hubo un tiempo en el que las cosas fueron de otra manera. Durante más de cinco siglos los estados, las confederaciones occidentales y del centro 
de Europa tuvieron y disfrutaron del llamado derecho común: el Ius Commune y una ciencia jurídica también común a todos esos mismos países y confederaciones. Cada biblioteca jurídica de un país o confederación europea del mundo medieval se remitió a los mismos fundamentos esenciales y a las mismas obras jurídicas. Así mismo, la formación de los juristas en todos los países se refería a los mismos basamentos. Ese derecho común era el derecho romano y canónico que desplegó su validez desde finales de la Alta Edad Media, hasta la época de la Revolución francesa en la Europa occidental y central.

La consolidación del derecho romano canónico como derecho común posee un origen político, histórico y cultural. Por un lado, la preeminencia política que afianzó la Iglesia Latina posgregoriana en la Edad Media -desde la dualidad de poderes existente entre el emperador y el papa- con la doctrina de las dos espadas y la disputa por la identificación del poder prevalente; debate que se dio entre lo secular y lo espiritual, con sus respectivas consecuencias jurídicas (Marquardt, 2016, p. 28). Por otro lado, el evidente proceso histórico cultural que se ha caracterizado por el acoplamiento, articulación e inserción del derecho canónico dentro del orden jurídico de los territorios europeos. Dicho proceso, en toda su magnitud y significaciones, se conoce hoy en día como la recepción.

En principio, el proceso de recepción del derecho romano abarcó una amplia complejidad en términos históricos y geográficos, pero esta lectura no aprecia otros elementos fundamentales. Dichas implicaciones históricas abarcan un periodo que se posiciona desde el redescubrimiento de Irnerio del ya olvidado Corpus Iuris Civilis en el 1080, luego en la denominada translatio imperii; además de los ya recurrentes conflictos sobre la superioridad entre el poder del emperador y el papa, reflejados en las reformas gregorianas y en la querella de las investiduras. A su vez, la recepción va unida al importante papel que de las recién fundadas universidades europeas, especialmente la de Boloña, la cual se convirtió en el centro de convergencia de los futuros juristas de toda Europa. Esta cuestión no fue simple, pues se debió también a la serie de prerrogativas concedidas a los estudiantes, lo cual llevó al fortalecimiento y difuminación de los conocimientos de la escuela de los glosadores a cada uno de los sistemas jurídicos de la Europa medieval (Castro, 2016).

Junto a la lectura histórica, es menester abordar las profundas imbricaciones dentro de la misma recepción, que implicó un proceso de aculturación en torno a una transmisión y reavivamiento de la cultura oriental europea, desde la Constantinopla de Justiniano, hasta la reinterpretación del Corpus Iuris Civilis por la inicial escuela boloñesa. A ese complejo proceso le continuó la confección de un sistema fundamentalmente canónico y procesal, que a su turno fundamentó su validez en la aculturación que, independientemente de las consideraciones axiológicas, implicó una interiorización del sistema jurídico. La interiorización de las normas éticas fue un proceso decisivo a la hora de validar los ordenamientos jurídicos y en razón a todo lo anterior, el derecho canónico resulta un fruto medieval (Grossi, 1996, p. 122) que se reafirma desde la sinergia previa entre el derecho romano y un derecho canónico que rescató aquello que consideró relevante para el orden social, donde, finalmente, los Studium fueron los mecanismos de transmisión y apropiación del conocimiento sobre el derecho antiguo.

A este punto de la discusión vale preguntarse sobre la noción de interiorización y ética. La importancia radica en que estas fueron el indicativo de apropiación del derecho romano por parte de los sistemas jurídicos receptores. Al respecto, se entiende la interiorización como la inmanencia de unos valores axiológicos en el individuo y, por supuesto, en la comunidad. Por otra parte, definir la ética resulta mucho más complejo.

En la tradición occidental es pertinente referir la conexión que se ha encontrado entre las ideas de ética y de estética y, por supuesto, las dificultades innegables en su aprehensión conceptual. Al respecto, vale citar la respuesta de Agustín cuando le preguntaban qué era el tiempo: "Si nadie me lo pregunta, lo sé; pero, si quiero explicárselo al que me lo pregunta, no lo sé" (De Hipona, 2010, p. 560). Así mismo, la cita de Umberto Eco cuando se refiere a la dificultad de juzgar desde las concepciones contemporáneas a las ideas de semejante 
complejidad y evolución a lo largo de la historia de la humanidad, así:

sobre el ideal de belleza, [estética o ética] "de una determinada época histórica, solo tenemos hoy tres tipos de testimonio y todos proceden de fuentes "cultas". Un extraterrestre que viniera a la Tierra hoy o dentro de mil años podría deducir qué tipo de belleza, de los cuerpos humanos, de los vestidos o de los objetos prefería la gente sencilla e ignorante de nuestro tiempo deduciéndolo de las películas, revistas ilustradas y programas de televisión. Pero nosotros, respecto a los siglos pasados, nos encontramos en las condiciones de un viajero llegado del espacio que, para decir cuál era nuestro ideal de belleza femenina, solo dispusiera del testimonio de Picasso (Eco, 2018, p. 39).

Las nociones de Agustín y de Eco sirven para evidenciar lo complejo que resulta, desde nuestra perspectiva, juzgar apriorísticamente el fenómeno de la aculturación que permitió la interiorización de las normas en siglos pasados. Basta referir la evidencia de que la conquista del Estado laico y la separación del Estado y la Iglesia son un avance innegable en el proceso de fortalecimiento institucional de los derechos de los particulares -desde la Revolución Francesa de 1789, hasta la Primera Enmienda a la Constitución de Filadelfia de 1776-, pero también es innegable que la interiorización de las normas jurídicas se entrelazó con la observancia de normas religiosas y éticas que permitieron durante la Baja Edad Media la consolidación jurídica normativa en la naciente Europa.

Dentro de la perspectiva defendida, según la cual es definitivo fortalecer insumos analíticos como la historia del derecho, vale la pena tomar con cierto detenimiento el concepto de recepción jurídica y cultural y, de manera descriptiva, hacer un recuento que exprese las omisivas falencias o precariedades que sufrió esa interiorización del sistema jurídico latinoamericano.

\section{El concepto de recepción}

El concepto acuñado de recepción no es una expresión histórica, sino que pertenece originalmente a la teoría de las fuentes del derecho. Una de las explicaciones de la validez del derecho romano en las diferentes naciones europeas durante la Edad Moderna, apunta a que se habría consolidado el uso del término a través del uso jurisdiccional y la costumbre Usu receptum. Esa comprensión fue sostenida especialmente en Alemania desde el siglo XVII, pero fue asumida de muchos otras latitudes y vecindades. Con la expresión Usu receptum se define el resultado de un proceso histórico, cultural y racional en una determinada categoría muy específica: la de la teoría de las fuentes del derecho. Sin embargo, sobre los acontecimientos históricos que han rodeado ese fenómeno poco se ha dicho. Vale apuntar que se trata de un proceso altamente complejo en términos históricos, culturales y sociológicos que se ha extendido por muchos siglos. Sin embargo, en el estrecho margen de medio siglo ha alcanzado, cada vez más, a todos los distintos países del continente. A pesar de que las condiciones en esos mismos países eran muy distintas, se generó un movimiento de grandes y significativas dimensiones que, en estrictos ámbitos interpretativos, son parecidos. Por supuesto, se manifestaron variaciones de territorio a territorio, de estado a estado, de burgo a burgo e incluso, de ciudad a ciudad; sobre todo considerables diferencias de validez en cuanto al tiempo de entrada en vigor de distintos apartes o normas. Sin embargo, en el área nuclear de las confederaciones de la Europa central en las que el derecho romano alcanzó una validez subsidiaria, se evidencia una comparación de los resultados jurídicos que se remite a la investigación jurídica local, pero que no permite una gran diferenciación de los fundamentos generales del derecho romano.

\section{Características generales}

La recepción, como aquí se plantea, ha sido un proceso de carácter histórico y jurídico. Esta tiene sus causas originales en el redescubrimiento científico del derecho romano, especialmente en Boloña, a través de juristas italianos durante los siglos XI y XII. Esa nueva vivificación es parte de un proceso más significativo que se encuadra en el renacimiento o revolución del siglo XII, término utilizado por Bloch (2011). En este tiempo surge en Europa una nueva conciencia: la necesidad de una 
percepción de la vida desde puntos de vista más científicamente fundamentados o menos conformistas con la unívoca visión interpretativa clerical. Este movimiento ha conducido a que los europeos nuevamente se adueñen de sus propios escritos antiguos. Esta frase puede sonar bastante simplista, pero conlleva toda una fenomenología social, pues la escritura y sobre todo la lectura, para el efecto que interesa, deja de ser episódica y se vuelve endémica al reconocer, redescubrir y reinterpretar todo el conocimiento antiguo a una realidad medieval que yacía en la ignorancia. Esto se ve claramente en el proceso de recuperación de la filosofía aristotélica con unas nuevas perspectivas. En el área del derecho ese proceso corresponde a su vez al redescubrimiento de todo el derecho justinianeo, en el llamado Corpus Iuris. Allí, los glosadores en Boloña encontraron un sistema jurídico relativamente completo que también, hasta un determinado grado, se podía trabajar científicamente y que satisfizo, hasta cierto punto, las inquietudes de ese tiempo.

Como se ha expuesto, durante el tardío siglo XI y todo el XII se concretaron en Boloña las bases del aprendizaje jurídico y, simultáneamente, se trabajó con los métodos de la ciencia de ese momento. Dentro de lo cual, no sobra repetir que se reavivó la comprensión lógica aristotélica de las observaciones.

\section{La legística y la canonística}

En el desarrollo del mismo movimiento comenzó también el trabajo científico del derecho canónico. Los canonistas podían recurrir libremente a una colección no oficial de las fuentes del derecho religioso, como la que estaba a disposición de los legistas en la reunión de la legislación de Justiniano. Al principio, en el estudio del derecho canónico surgieron las colecciones que edificaron su propio papel en la conformación clásica y primigenia de este derecho. Una colección temprana fue realizada por Ivo de Chartres -Ivonis Carnutensis- (Grossi, 1996), quien hacia el 1080, en medio del ya mencionado conflicto de las investiduras y las reformas papales, realizó un tratado metodológico para los canonistas en el que ya se vislumbraban fragmentos jurídicos romanos y un deseo inacabado de sistematicidad en la normatividad canónica. Aun así, y en razón a su posición clerical, para Ivo existía una clara preponderancia del derecho canónico sobre las normas conocidas aplicables del derecho romano, en tanto estas últimas, para su aplicación específica, requerían ser aceptadas por la iglesia. No fue sino hasta el 1140 en Boloña, con la aparición del Decretum Gratiani, que se intentó proveer de un aire armónico al derecho canónico. El significativo avance que trajo consigo el Decretum llevó a que hacia el 1160 se considerara como un área jurídica de estudio similar al derecho romano (Stein, 2000). Así fue como la obra de Graciano, junto al Corpus Iuris Civilis, se convirtió en homóloga para el estudio del derecho canónico por los legistas y se consolidó como materia de trabajo científico en las clases universitarias.

Al desaparecer la inicial desventaja del derecho canónico frente al derecho romano, en tanto este último poseía el Corpus como objeto de estudio delimitado y sistematizado, fue posible el desarrollo científico del derecho canónico. Esto no solo se vio en su dimensión académica, sino que la constante e ininterrumpida legislación aplicada en la actividad decisoria de los tribunales y los papas, llevaron a que la disciplina alcanzara un mayor grado de complejidad y sistematicidad.

De esta manera surgió el Ius Utrumque en la Europa medieval. Así, el derecho válido estaba conformado tanto por el Corpus Iuris Civilis, como por el Corpus Iuris Canonici, integrado en su generalidad por el Decretum Gratiani y sus modificaciones complementarias.

\section{El papel de las universidades}

Para esta época, un punto que definió el surgimiento del derecho europeo tiene que ver con que el derecho canónico alcanzó validez y fuerza a través de las decisiones de los papas medievales, expedidas en normas -sin ningún otro elemento adicional-, en toda la dimensión de la Iglesia católica y latina. Así pues, solo puede hablarse de una recepción en el sentido ya esquematizado aquí, en la medida en que se discuta sobre la certera adopción de las reglas canonistas en el derecho europeo. Una cuestión particular muy poco aclarada hasta ahora. 
Para la propagación del derecho romano hay dos hechos históricos de una decisiva significación. El primero radica en que desde el siglo XII, Boloña y otras escuelas jurídicas italianas y francesas se han convertido en centros de investigación jurídica internacional y del estudio jurídico. Y el segundo, que todas las nuevas facultades de derecho fundadas en la Edad Media han adoptado como único material de trabajo en la investigación y la cátedra, el así concebido y ya descrito Ius Utrumque.

Para la significación de Boloña sería necesario también remitirse al Emperador Federico Barbarroja, quien para el 1158 otorgó un privilegio real a los estudiantes; acto que con una muy poca frecuencia se dictó, lo que resulta comprensible para el momento histórico de entonces. Para el año 1266 se podían contar, más o menos, un millón de estudiantes de ultramontana en la ciudad de Boloña. En esa misma época es que aparece reconocible el uso de analogías religiosas para indagar o adjudicar razones de ley. Berman (1996) menciona que "las metáforas de anteayer son las analogías de ayer y los conceptos de hoy" (p. 177). Poco a poco, la noción de mito jurídico deja de tener la significación de fábula, para convertirse en una forma de verdad sagrada.

Dentro de la migración de lo religioso a lo jurídico, tal vez lo más importante tenga que ver con la sacralidad de la palabra que se otorgó inicialmente al texto bíblico y posteriormente al texto o corpus que resumía y contenía todas las proporciones jurídicas que podían resolver los entuertos entre los particulares (Berman, 1996). El juicio, como readecuación humana del juicio final y divino; el purgatorio, como forma de purgar las penas y reivindicar el error cometido en contra de la sociedad y la absolución ya no de los pecados, sino de los delitos o las contravenciones.

Muchos han escrito sobre la concordancia simbólica y semiológica, así como la conceptual y disuasiva que existe entre las ritualidades, instituciones, conceptos y valores básicos de los sistemas jurídicos occidentales, con los rituales y doctrinas de la religión católica de los siglos XI y XII, los cuales reflejan nuevos posicionamientos frente a la muerte, el pecado, el castigo y, sobre todo, el perdón y la salvación (Clavero, 1984; Grossi, 1996;
Salinas, 1996). Por supuesto, la relación de lo humano con lo divino y de la fe con la razón sufrió modificaciones significativas.

Parte de la grandeza de la invención jurídica en todas las sociedades gravita en torno al reconocimiento de la imperfección humana. Esta idea reposa sobre el convencimiento de que la vida es una especie de escuela o de aprendizaje, de lección necesaria para retornar a un estado que por alguna falta humana se perdió. De otro lado, desde un punto de vista más empírico, el ser humano ameritaba una vida social que comenzaba con la dependencia del niño a la madre, eventualmente al padre y luego durante toda su existencia para procurarse un mejor bienestar.

Esa primera noción determinó en el judaísmo y cristianismo la noción de un Dios entendido como juez justo y misericordioso que ampliaría al máximo las posibilidades de salvar a sus hijos, con la condición de rechazar y oponerse al pecado y a la falta (Berman, 1996). A su turno, parece que históricamente se da cuenta de la juridicidad cristiana primitiva en relación con la observancia necesaria que tan solo algunos de los primeros cristianos hacían de la juridicidad judía y romana, mas no existía una noción propia de derecho por parte del cristianismo.

Berman adjudica la noción de desobediencia civil a los primeros tiempos de la Iglesia católica, pues el culto cristiano era ilegal. La conversión de Constantino y luego de los reyes francos y germanos comportó la escabrosa pregunta de si la cristianización implicaba una necesidad de reforma en la interpretación del derecho romano, lo que en últimas -no queda claro si de buen o mal recibodesembocó en una serie de reformas puntuales durante los siglos III al vi. Estas se entienden como la cristianización de la legislación romana: a la mujer se le dio una posición de mayor igualdad, el consentimiento para el matrimonio debía ser mutuo y el divorcio se vuelvió causalista, mucho más restringido que dentro del derecho romano clásico; el esclavo tenía derecho a denunciar los abusos de su amo y se consideró como hijo de Dios, condición previa a su conversión al cristianismo; se entroniza la equidad y la analogía como forma prevalente de interpretación, por sobre la exégesis formalista romana clásica. 
Por supuesto, el cristianismo se avivó inicialmente de manera apocalíptica pero, poco a poco, diseminó entre todas las culturas antiguas que acogían la fe las visiones e interpretaciones diversas que estimularon la relectura humanizadora del derecho del imperio romano de Oriente y Occidente. Pero en Occidente, la ausencia de escuelas y de una clase profesional de juristas, así como de una permanente y sistemática discusión, casi sepultaron al derecho romano en un profundo olvido. Por el contrario, en Oriente las escuelas, las universidades, la profesionalización de los juristas y la discusión permanente lograron que el derecho perviviera de Constantinopla a Bizancio. Fue el mismo Justiniano, quien al prohibir los comentarios a sus leyes, provocó un mayor aletargamiento y olvido de su propia sistematización. En Oriente y Occidente la noción de justicia se reemplazó por la noción de concordancia con los textos bíblicos, proceso que se dio de la mano de la naciente teología, que buscaba brindar bases al estudio de las sagradas escrituras.

A partir de la transmisión de contenidos axiológicos, metáforas y analogías, es decir, de lo teológico a lo jurídico, se advierte en la transición del pensamiento cristiano al derecho la mediación de un estudio racional del dogma cristiano que, a grandes rasgos, fue aquello que permitió la paulatina evolución del derecho. En dicho escenario, el juego de la indisociabilidad de categorías éticas como la justicia y la misericordia fueron puentes que tuvieron serias implicaciones posteriores en el pensamiento jurídico, como es evidente en la llamada doctrina de la expiación de Anselmo (Berman, 1996). De esta manera, en el campo teológico, la identificación de lo justo con lo misericordioso y viceversa, junto a la inherente percepción de la necesidad de la penitencia como único mecanismo para alcanzar el perdón divino, llevó a que Anselmo acudiera al derecho como instrumento para la materialización de lo anterior, de modo que ya no se trataba de una noción de justicia moral, sino que desde lo religioso se empezó a copar lo jurídico.

En aquel momento el fundamento de la existencia del derecho penal, en razón a la directa relación con la teoría de la expiación, tomaba sus bases no como una lesión a un bien jurídico o interés colectivo, sino que estaba directamente relacionado con la ofensa causada a la víctima, a su familia y a Dios, por lo cual el delito era un pecado. Progresivamente, las consideraciones en torno al pecado no solamente contemplaron una dimensión retributiva divina, de resarcimiento del honor o de los derechos violados a la víctima, sino que reforzaron una postura legalista en torno al pecador, con lo que sería un criminal, alguien objeto de castigo divino e institucional (Berman, 1996). De este modo, la doctrina giró en torno a dos ejes duales fundamentales: la relación del delito con el pecado y del castigo con la expiación.

A su vez, no es de ignorar el papel del derecho procesal en la armonización y sinergia entre el derecho canónico y el derecho romano. Cuando los canonistas hicieron uso del derecho sustancial romano rescatado del Corpus para llenar los vacíos de sus propias normas, no solamente tomaron dichos elementos, sino que también llegaron a nuevos conceptos y sistematizaciones en el ámbito procesal. Como lo menciona Cappelletti y Perilo (1965) "al principio, la fusión de los dos sistemas avanzó de manera lenta y casi imperceptiblemente. [De tal modo,] Fue creado un nuevo sistema sustantivo y procesal, ahora conocido como romano-canónico o italo-canónico" (p. 33). Dicha fusión, permitió el perfilamiento simbólico del derecho y específicamente del orden judicial, como fuente de deberes para las partes del proceso y que, ante la negligencia de las partes, tuvo severas consecuencias de tipo coercitivo y sancionatorio, como lo fue la excomunión; todo ello derivado de la contumacia (Pérez, 2008). Así mismo, con el ambivalente estudio de ambas disciplinas jurídicas, aparecen juristas que conciben el proceso desde su separación entre "la acción, las partes, los argumentos de la demanda y de la defensa, la prueba, la sentencia y las apelaciones" (Stein, 2000, p. 83), perfilando aún más el proceso judicial, casi como lo concebimos hoy en día.

Desde el derecho sustancial y procesal, lo anterior llevó a formar parte del proceso de racionalización de Europa. En términos de Weber (1987) esto "solo se ha conseguido merced a la recepción por los juristas italianos de la antigua jurisprudencia romana, producto de una forma política 
totalmente única que nace como ciudad-estado para convertirse en imperio mundial" (p. 67). A partir de la jurisprudencia contenida y decantada en el Corpus Iuris Civilis, fue que el derecho de la Alta Edad Media pudo empezar a gozar de sistematicidad, abstracción, formalización y racionalización. Así, el derecho canónico y particularmente su conjunción en Ius Utrumque se convirtió en un punto de partida para el surgimiento de "un derecho natural no religioso, que terminaría desembocando en sucesos revolucionarios y la tendencia positivista que cobra la doctrina jurídica desde el siglo XIX en consonancia con la secularización de pensamiento que siguió al desarrollo científico y técnico" (Munné, 2006, p. 81). De esta manera, bajo la égida del derecho racional obtenido a través de la incorporación y estudio del derecho romano, se pudo gestar el medio propicio para el capitalismo, que aseguró su surgimiento a través de la seguridad que traía consigo un derecho mejor elaborado (Giddens, 2007).

\section{Conclusiones}

A partir de lo anteriormente analizado, es dable afirmar que gracias al contenido semiológico, valorativo y axiológico, producto de la unión del derecho canónico y el derecho romano, se sentaron las bases para la funcionalidad y eficacia de los sistemas europeos. Del mismo modo, las consecuencias del proceso de estudio, apropiación y diseminación del derecho romano y canónico de la Alta Edad Media perduran hasta nuestros días y fueron el germen de la sociedad moderna.

No obstante, es imposible decir lo mismo en el caso de los países latinoamericanos. Quizás una real apropiación de los conocimientos existentes al momento de la colonización hubiera llevado a una mejor adecuación de las normas para los habitantes del continente. Mientras tanto, con la copia de las normas europeas del momento solo se puede reafirmar la colonialidad del poder y del saber a la que han estado condenadas.

Desde el derecho europeo y particularmente el español, el proceso de recepción no ocurrió en nuestros sistemas jurídicos. Esta es la razón fundante de la ineficacia normativa que impera. Adicionalmente, el grado de complejidad que poseen los sistemas sociales impiden que se revista de un proceso histórico que llegue a asimilarse al de la Edad Media, con lo cual las atribuciones no llegarán a ser las mismas. El valor simbólico que se le imprimió al derecho en la época colonial no fue el mismo al que le fue atribuido en las sociedades europeas en la Edad Media.

\section{Referencias}

Berman, H. (1996). La formación de la tradición jurídica de Occidente. México: Fondo de Cultura Económica.

Bloch, M. (2011). La sociedad feudal. España: Cofás s.A.

Cappelletti, M., Perilo, J. (1965). Civil procedure in Italy. New York: Springer-Science+Business Media, B.V. doi: https://doi.org/10.1007/978-94-017-6273-1

Castro, G. (2016). De la histórica articulación del derecho civil y el derecho público: un caso reivindicatorio. $R e-$ vista Pensamiento Jurídico, (43), 59-100. Recuperado de: https://revistas.unal.edu.co/index.php/peju/article/view/60704

Clavero, B. Religión y derecho: mentalidades y paradigmas. Revista Historia. Instituciones. Documentos, (11), 6792. Recuperado de: https://idus.us.es/bitstream/handle/11441/14152/file_1.pdf?sequence=1\&isAllowed $=y$

Comisión Económica para América Latina y el Caribe (Cepal). (2002). Globalización y desarrollo. Brasil. Recuperado de: https://repositorio.cepal.org/bitstream/ handle/11362/2724/2/S2002024_es.pdf

De Hipona, A. (2010). Confesiones. España: Editorial Gredos.

Ferro, M. (2000). La colonización. Una historia global. México: Siglo Veintiuno Editores.

Giddens, A. (1997). Política, sociología y teoría social: reflexiones sobre el pensamiento social clásico y contemporáneo. Barcelona: Editorial Paidós.

Grossi, P. (1996). El orden jurídico medieval. Barcelona: Editorial Marcial Pons.

Marquardt, B. (2016). El Espejo Sajón de 1225: Derecho público del Medioevo europeo en imágenes. Revista Pensamiento Jurídico, (43), 17-58. Recuperado de: https://revistas.unal.edu.co/index.php/peju/article/ view/60699

Munné, G. (2006). Racionalidades del Derecho según Max Weber y el problema del formalismo jurídico. Isonomía, (25), 69-100. Recuperado de: http://www. scielo.org. $\mathrm{mx} /$ scielo.php?script $=$ sci_arttext\&pi$\mathrm{d}=$ S1405-02182006000200005\#notas 
Palacios, M. (2003). Entre la legitimidad y la violencia. Colombia 1875-1994. Bogotá: Editorial Norma.

Pérez, Á. (2008). La rebeldía en diversos modelos procesales de la Edad Media, paralelos, variables y evolución de la figura. Revista de estudios Histórico-Jurídicos, (30), 289-314. Recuperado de: http://www.redalyc.org/ articulo.oa?id=173819211011

Posada, C. (2010). 1910 y 2010: dos momentos y cien años. En: Calderón, M., Restrepo, I. Colombia 1910 - 2010. Bogotá: Taurus.

Salinas, C. (1996). Una aproximación al derecho canónico en perspectiva histórica. Revista de estudios Histórico-Jurídicos, (18), 289-360. Recuperado de: http:// www.rehj.cl/index.php/rehj/article/viewFile/250/238

Schwartz, P., Rodríguez, C. (1992). Las relaciones entre Jeremías Bentham y Simón Bolívar. Revista Iberoamericana de Estudios Utilitaristas, 1(3), 45-68. doi: https:// doi.org/10.15304/t.1.3.938

Stein, P. (2000). El Derecho Romano en la historia de Europa: historia de una cultura jurídica. España: Siglo XXI de España Editores.

Valencia, H. (1987). Cartas de Batalla: una crítica del constitucionalismo colombiano. Bogotá: Universidad Nacional de Colombia.

Weber, M. (1987). Ensayos sobre sociología de la religión I. Madrid: Taurus. 